\title{
BMJ Open Metoprolol for prophylaxis of postoperative atrial fibrillation in cardiac surgery patients: systematic review and meta-analysis
}

\author{
Mohd Noor Norhayati (D , ${ }^{1}$ Ismail Shaiful Bahari, ${ }^{1}$ Sulaiman Zaharah, ${ }^{2}$ \\ Nik Hussain Nik Hazlina, ${ }^{2}$ Zainuddin Mohammad Aimanazrul, ${ }^{1}$ \\ Muhammad Irfan (i) 2,3
}

To cite: Norhayati MN, Shaiful Bahari I, Zaharah S, et al. Metoprolol for prophylaxis of postoperative atrial fibrillation in cardiac surgery patients: systematic review and meta-analysis. BMJ Open 2020;10:e038364. doi:10.1136/ bmjopen-2020-038364

- Prepublication history and additional material for this paper is available online. To view these files, please visit the journal online (http://dx.doi.org/10. 1136/bmjopen-2020-038364).

Received 23 March 2020 Revised 10 September 2020 Accepted 22 September 2020

Check for updates

C Author(s) (or their employer(s)) 2020. Re-use permitted under CC BY-NC. No commercial re-use. See rights and permissions. Published by BMJ.

${ }^{1}$ Department of Family Medicine School of Medical Sciences, Health Campus, Universiti Sains Malaysia, Kubang Kerian, Malaysia

${ }^{2}$ Women's Health Development Unit, School of Medical Sciences, Health Campus, Universiti Sains Malaysia, Kubang Kerian, Malaysia ${ }^{3}$ Department of Zoology, Pir Mehr Ali Shah, Arid Agriculture University, Rawalpindi, Pakistan

Correspondence to

Professor Mohd Noor Norhayati; hayatikk@usm.my

\section{ABSTRACT}

Purpose Postoperative atrial fibrillation (POAF) is a potentially lethal and morbid complication after open heart surgery. This systematic review and meta-analysis aimed to investigate metoprolol compared with other treatments for prophylaxis against POAF.

Methods We searched CENTRAL, MEDLINE, EMBASE and trial registries for randomised controlled trials that evaluated metoprolol for preventing the occurrence of POAF after surgery against other treatments or placebo. Random-effects model was used for estimating the risk ratios (RRs) and mean differences with $95 \% \mathrm{Cls}$.

Results Nine trials involving 1570 patients showed metoprolol reduced POAF compared with placebo ( 416 patients; RR $0.46,95 \% \mathrm{Cl} 0.33$ to 0.66 ; $\mathrm{I}^{2}=21 \%$; risk difference (RD) $-0.19,95 \% \mathrm{Cl}-0.28$ to -0.10 ). However, metoprolol increased the risk of POAF compared with carvedilol (159 patients; RR $1.59,95 \% \mathrm{Cl} 1.20$ to 2.12 ; $\mathrm{I}^{2}=4 \% ; \mathrm{RD} 0.13,95 \% \mathrm{Cl} 0.06$ to 0.20$)$. There was no difference when compared with sotalol or amiodarone. The occurrence of cardiovascular conditions after drugs administration or death between the groups was not different. The overall quality of evidence was moderate to high. Subgroup analysis and funnel plot were not performed.

Conclusions Metoprolol is effective in preventing POAF compared with placebo and showed no difference with class III antiarrhythmic drugs. Death and thromboembolism are associated with open heart surgery, but not significant in relation to the use of metoprolol.

PROSPERO registration number CRD42019131585.

\section{INTRODUCTION}

Postoperative atrial fibrillation (POAF) is the most important type of secondary AF, representing a new-onset $\mathrm{AF}$ in the immediate period after cardiac surgery. ${ }^{1} \mathrm{POAF}$ is a potentially lethal and morbid complication after open heart surgery; it is reported that POAF occurs in $20 \%-40 \%$ of cardiac-related surgery and $10 \%-20 \%$ of non-cardiac operations. ${ }^{1}$ This complication is characterised by episodes that are often brief, asymptomatic
Strengths and limitations of this study

- Meta-analysis of randomised controlled trials

- Cochrane methodology.

- Grading of Recommendations Assessment, Development and Evaluation quality assessments.

- Subgroup analysis was not performed.

- Funnel plot was not performed.

and paroxysmal, usually peaking between the second and fourth days postoperatively. Patients undergoing concomitant valvular heart surgery have a higher incidence of AF, which may reach $64 \%$. $^{2}$

The POAF is usually self-limiting in patients with no prior history of AF, resolving spontaneously without any interventions. ${ }^{3}$ Although seen as a temporary problem related to cardiac surgery, POAF can lead to morbidity and mortality in high-risk patients. ${ }^{4}$ The development of POAF is associated with increased risk of thrombotic events, such as stroke, thrombophlebitis, myocardial infarction and prolonged hospital stay. It is estimated that this problem will continue to grow, given that the patient population undergoing cardiac surgery is ageing, and the incidence of POAF is largely age dependent. ${ }^{4}$

The aetiology of POAF is multifactorial and contributed to by certain factors, such as systemic and local inflammation and oxidative stress, as well as electrolyte imbalance. ${ }^{5} \mathrm{AF}$ in the postoperative period is due to ectopic firing or re-entry. This occurs because of the presence of an atrial substrate produced by the postoperative remodelling process after cardiac surgery. ${ }^{1}$ Pharmacological agents that have been extensively used in POAF prophylaxis are beta-blockers and amiodarone, while non-pharmacological agents include atrial pacing. Currently, there are no definitive 
preventive strategies for AF following heart surgery. ${ }^{6}$ There were a few meta-analyses for the evaluation of metoprolol for prophylaxis of $\mathrm{POAF}^{78}$; following which, new trials were included in this review. The aim of this review is to investigate metoprolol in comparison with control for prophylaxis against POAF in order to reduce the occurrence of adverse events in the postoperative period, such as death and cardioembolic events. We hypothesised that metoprolol is effective for prophylaxis against POAF compared with other treatment options.

\section{MATERIALS AND METHODS}

The methodology and reporting were based on recommendations from the Cochrane Collaboration ${ }^{9}$ and the Preferred Reporting Items for Systematic Reviews and Meta-Analyses statement ${ }^{10}$; the evaluation was conducted according to the Grading of Recommendations Assessment, Development and Evaluation (GRADE) guidelines. ${ }^{11}$

\section{Eligibility criteria}

We considered randomised controlled trials (RCTs) comparing metoprolol with placebo (or no treatment) or other drugs that are commonly used in POAF prophylaxis. We included blinded and open-label studies. The intervention was intravenous or oral metoprolol used perioperatively, during hospitalisation, for preventing the occurrence of POAF after surgery. The comparisons included placebo or other drugs commonly used for the prevention of POAF. We considered for inclusion trials that included patients who underwent cardiac surgery (both revascularisation and valve surgery) without prior or concomitant AF. There were no restrictions on age or other comorbidities, such as hypertension and diabetes. We only considered publications that were published in the English language.

\section{Search strategy}

We searched the Cochrane Central Register of Controlled Trials (CENTRAL 2019, Issue 3), MEDLINE, EMBASE and trial registries (till March 2019). The searches for systematic reviews aim to be as extensive as possible to ensure that the review includes as many of the necessary and relevant studies as possible. However, when developing a search strategy, a balance must be struck between striving for comprehensiveness or sensitivity and maintaining relevance or precision. Increasing a search's sensitivity will reduce its precision, and more non-relevant articles will be retrieved. ${ }^{9}$ We have combined the concepts of population, intervention and study design based on the text words 'metoprolol', 'beta blocker' and 'AF' and Boolean operators like AND, OR, truncation and wildcards for variations in words to have a balance in the sensitivity and precision of the search strategy. We checked the reference list of the identified RCTs and review articles to find unpublished trials or trials not identified by the electronic searches. We also searched for ongoing trials through WHO International Clinical Trials Registry Platform (ICTRP) and ClinicalTrials.gov.

\section{Trial selection}

Two review authors (MNN and ZMA) scanned the titles and abstracts independently from the searches and obtained full-text articles when they appeared to meet the eligibility criteria, or there was insufficient information to assess eligibility. We independently assessed the eligibility of the trials and documented the reasons for exclusion. We resolved any disagreements between the review authors by discussion. We contacted the trial authors if clarification was needed.

\section{Data extraction}

Using the data extraction form, the review authors (MNN, ZMA) independently extracted the characteristics of the trials (study setting), participants' characteristics (age, sex, ethnicity, comorbidities), methodology (number of participants randomised and analysed, duration of follow-up), description of the intervention (dosage, route of administration) and outcomes. When information was missing or inadequately reported, we tried to contact the corresponding authors for the trial.

The predefined primary outcome was the occurrence of a first POAF. The primary outcome refers to the number of patients having POAF during the postoperative period as diagnosed by a physician on ECG. The ECG monitoring was either performed as continuous monitoring or when a patient had palpitation or screened in the ward in the postoperative period. The secondary outcomes were the occurrence of adverse events (stroke, the occurrence of hypotension as reported by the clinicians and bradycardia after administration of drugs and death during the postoperative period).

\section{Assessment of risk of bias}

We assessed the risk of bias based on random sequence generation, allocation concealment, blinding of participants and personnel, blinding of outcome assessors, completeness of outcome data, the selectivity of outcome reporting and other bias, as discussed in the Cochrane Handbook for Systematic Reviews of Interventions. ${ }^{9}$ We categorised the risk of bias as low, unclear or high.

\section{Statistical analysis}

All the statistical analyses were performed using Review Manager (RevMan) V.5.3.5 (Nordic Cochrane Centre, Cochrane Collaboration). For all the included trials with categorical outcomes, we calculated the risk ratios (RRs), risk difference (RD) and 95\% CIs, and for numerical outcomes, we calculated the mean differences and 95\% CIs. If data from two or more trials were included in an analysis of an outcome, we reported the results of random-effects model.

We assessed the presence of heterogeneity via two steps. First, we assessed obvious heterogeneity at face value by comparing populations, settings, interventions and outcomes. Second, we assessed statistical heterogeneity by 


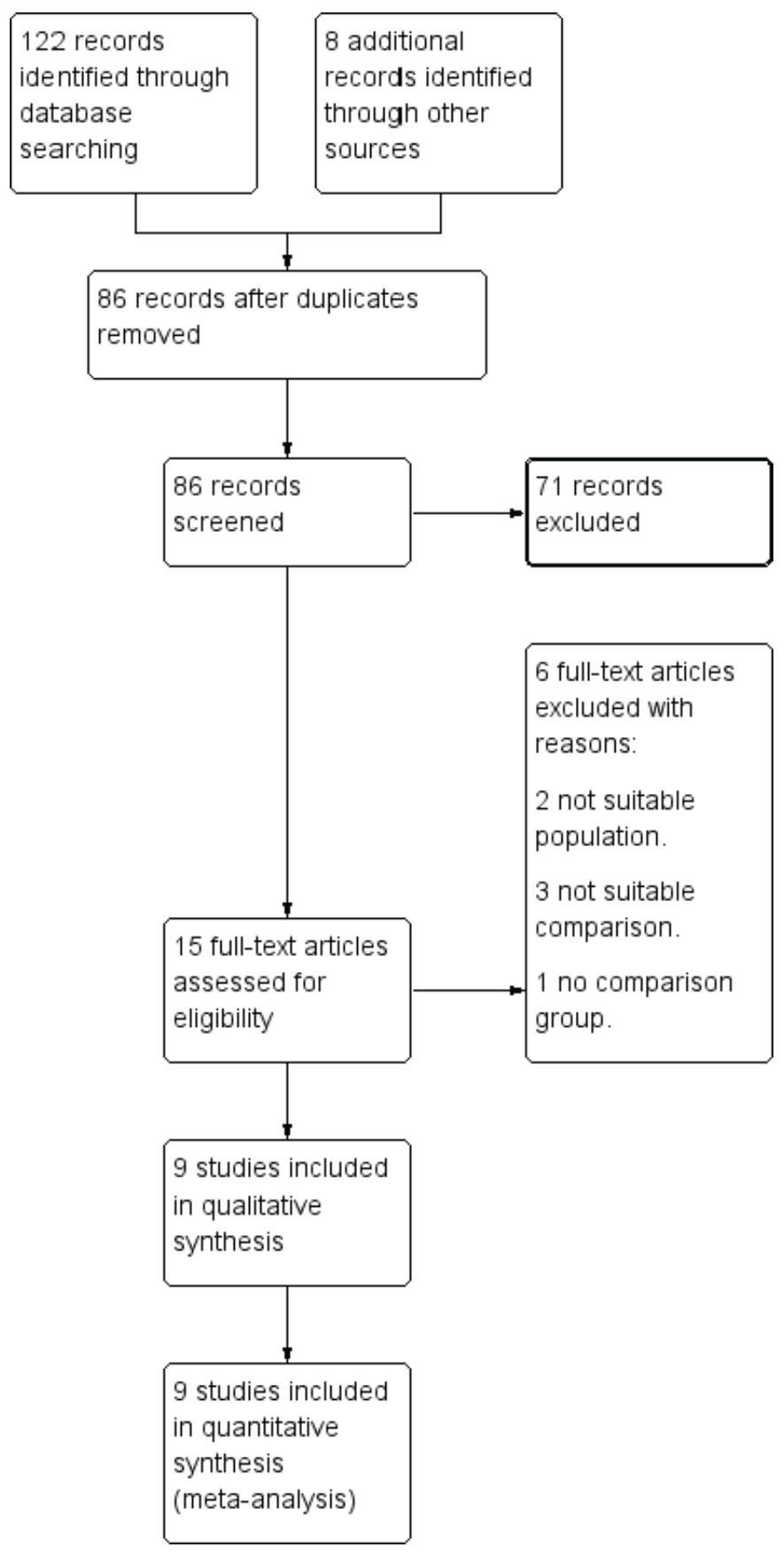

Figure 1 Flow chart of the selected studies.

means of the $\mathrm{I}^{2}$ statistic: $0 \%-40 \%$, may not be important; $30 \%-60 \%$, may represent moderate heterogeneity; $50 \%-90 \%$, may represent substantial heterogeneity and $75 \%-100 \%$, represents considerable heterogeneity. ${ }^{9}$

If possible, we conducted subgroup analyses on patient age, comorbidities and the mode of drug administration. We performed a sensitivity analysis for investigating the effect of risk of bias for sequence generation and allocation concealment of the included studies.

\section{Grading quality of evidence}

We used the principles of the GRADE approach for evaluating the quality of evidence in systematic reviews. ${ }^{11}$ This approach specifies four levels of quality, the highest of which is for randomised trial evidence. It can be downgraded to moderate, low or even very low-quality evidence, depending on the presence of the following four factors: (1) limitations in the design and implementation of available studies, (2) indirectness of evidence, (3) unexplained heterogeneity or inconsistency of results and (4) imprecision of results. We used the GRADEpro GDT software (Evidence Prime) for reflecting the quality of evidence for each individual outcome, and the assessment was phased in together with the summary of findings table.

\section{Patients and public involvement}

Patients and the public were not involved in the design or planning of the study.

\section{RESULTS}

\section{Trial selection}

We retrieved 122 records from the search of the electronic databases and 8 records from other sources (figure 1). We screened 86 records, excluded 71 records that obviously did not fulfil the eligibility criteria based on the title and abstract and reviewed the full texts of 15 studies. We identified nine articles as meeting the review inclusion criteria, while six were not eligible for inclusion. Two trials were excluded because they were not conducted on heart surgery patients, ${ }^{12} 13$ three because they included unsuitable comparators ${ }^{14-16}$; one was on dose-dependent effect of metoprolol. ${ }^{17}$ There were no ongoing trials found during the search process.

\section{Characteristics of trials}

We included nine trials with a total of 1570 participants. All the trials contributed to the primary outcome. Four trials related to the secondary outcomes, which were the occurrence of death and stroke ${ }^{1819}$ and occurrence of bradycardia and hypotension. ${ }^{20} 21$ Table 1 summarises the characteristics of the included trials.

\section{Participants}

Eight ${ }^{618-2022-25}$ of the nine included trials were conducted in high-income countries in Europe, while one was from a South American country. ${ }^{21}$ All the trials were from a single centre except one that involved three cardiac centres in Finland..$^{18}$ The trials were conducted in patients that underwent cardiac surgery, including coronary artery bypass surgery and valvular heart surgery. In all the trials, patients were excluded if they had a history of arrhythmia.

\section{Interventions}

Three trials were compared against placebo or no treatment, ${ }^{202124}$ four against carvedilol, ${ }^{6222325}$ two against amiodarone ${ }^{1819}$ and two against sotalol. ${ }^{2024}$ The routes of administration for metoprolol were oral, ${ }^{6}{ }^{19-23} 25$ intravenous ${ }^{18}$ and both oral and intravenous ${ }^{24}$ and the range of doses given per day was 100-200 mg. Sotalol, amiodarone and carvedilol were given in the same fashion, and the doses were titrated based on the patients' heart rates and 


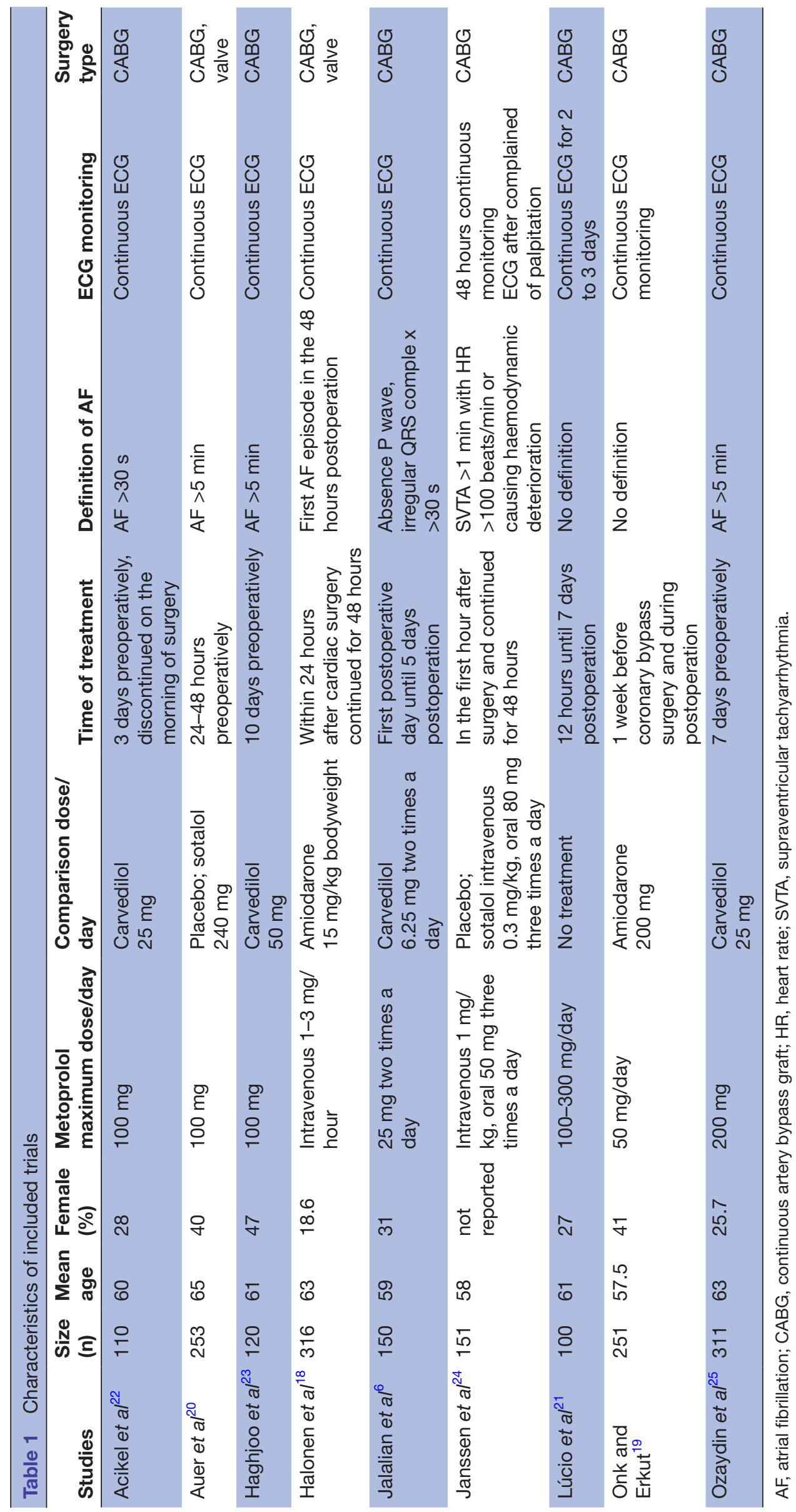




\section{Random sequence generation (selection bias)}

Allocation concealment (selection bias)

Blinding of participants and personnel (performance bias)

Blinding of outcome assessment (detection bias)
Incomplete outcome data (attrition bias)
Selective reporting (reporting bias)

Blinding of outcome assessment (detection bias)
Incomplete outcome data (attrition bias)
Selective reporting (reporting bias)

Blinding of outcome assessment (detection bias)
Incomplete outcome data (attrition bias)
Selective reporting (reporting bias)

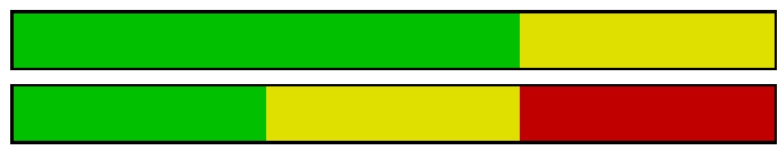

Other bias
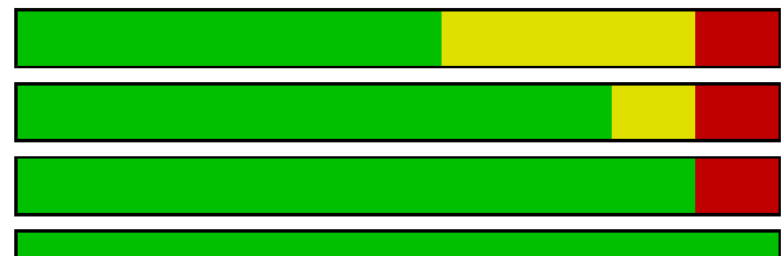

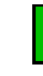

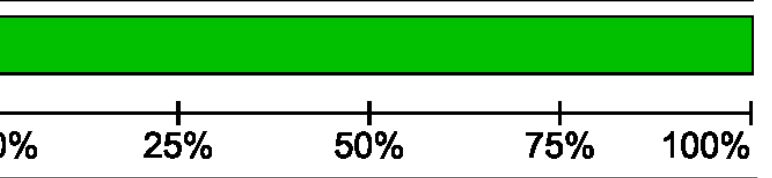

\section{Low risk of bias}

Unclear risk of bias

High risk of bias

Figure 2 A graph of the risk of bias according to review authors' judgements about each risk of bias item presented as percentages across all included studies.

tolerance levels. The drugs were given preoperatively in some studies, and some were given in the immediate postoperative period or in the morning post-operatively. The drugs were continued in the postoperative period in the intensive care unit (ICU) or postoperative ward. The patients were then monitored on continuous ECG monitoring with a time ranging from 2 days to until discharge.

\section{Outcomes}

All the trials reported the occurrence of AF in the postoperative period with continuous ECG monitoring in the ICU and in the ward. POAF was reported as the first occurrence of AF in the postoperative period; however, the period of monitoring was not consistent throughout the trials. It ranges from immediately after surgery until 7 days postoperation or discharge from hospital. Three trials reported the results of metoprolol versus placebo. ${ }^{20} 2124$ Two trials involved comparisons with sotalol, ${ }^{20} 24$ two with amiodarone $^{1819}$ and four with carvedilol. ${ }^{6222325}$

\section{Assessment of risk of bias}

The assessment of risk of bias is shown in figures 2 and 3. Figure 2 shows the proportion of studies assessed as having low, high or unclear risk of bias for each risk of bias indicator. Figure 3 shows the risk of bias indicators for individual studies. All the trials described the method of randomisation for participant allocation except one. ${ }^{24}$ Six trials applied the simple randomisation technique. ${ }^{61921-2325}$ One trial used block randomisation, ${ }^{18}$ and another used a randomisation table. ${ }^{20}$ Allocation concealment was not mentioned in five trials, ${ }^{62-25}$ and concealment was not performed in two trials. ${ }^{1921}$ Only two trials mentioned their method of concealment, where concealment was designated via envelopes opened in sequence ${ }^{18}$ and concealment by means of opaque capsules. ${ }^{20}$ Two trials did not mention blinding of participants, ${ }^{21} 24$ while two trials were open-labelled trials. ${ }^{18} 19$ Four trials employed participant blinding. ${ }^{6202223}$

All the trials reported the outcomes as specified in their objectives. Owing to the short follow-up periods in the studies, none of the trials had lost to follow-up. Two trials mentioned that they performed an intention-to-treat analysis. $^{2021}$ The other trials did not mention the intention to treat principle analysis, but the participants were analysed according to the groups to which they were initially assigned. ${ }^{6181922-25}$ All nine trials reported the outcomes as specified in their methods. ${ }^{6-25}$ None of the trials were registered in the WHO ICTRP or ClinicalTrials.gov. We detected no other potential sources of bias.

\section{Clinical outcomes}

The primary outcome, that is, the occurrence of a first POAF was measured in all the trials. The secondary outcomes (stroke, hypotension, bradycardia and death) were only measured in four trials, ${ }^{18-21}$ which limits our analysis of the secondary outcomes to comparisons between the amiodarone and placebo groups only.

\section{Postoperative atrial fibrillation}

In the metoprolol versus placebo comparison, three trials reported the occurrence of POAF. ${ }^{202124}$ There was significant reduction in POAF (416 patients; RR 0.46, 95\% CI 0.33 to $0.66 ; \mathrm{I}^{2}=0 \%$; $\mathrm{RD}-0.19,95 \%$ CI -0.28 to $-0.10 ; \mathrm{p}$ $<0.001$ ) (figure 4). The GRADE quality assessment for this outcome was moderate (table 2).

In the metoprolol versus carvedilol comparison, four trials reported the occurrence of $\mathrm{POAF}^{622} 2325 \quad(587$ patients; RR $1.59,95 \%$ CI 1.20 to 2.12 ; $\mathrm{I}^{2}=4 \%$; RD 0.13 , $95 \%$ CI 0.06 to $0.20 ; \mathrm{p}=0.001$ ) (figure 5 ). In this comparison, the dose of metoprolol ranged between 50 and 200 mg per day, and carvedilol ranged between 12.5 and 25 mg per day. The heterogeneity of the trials was low at $4 \%$ 


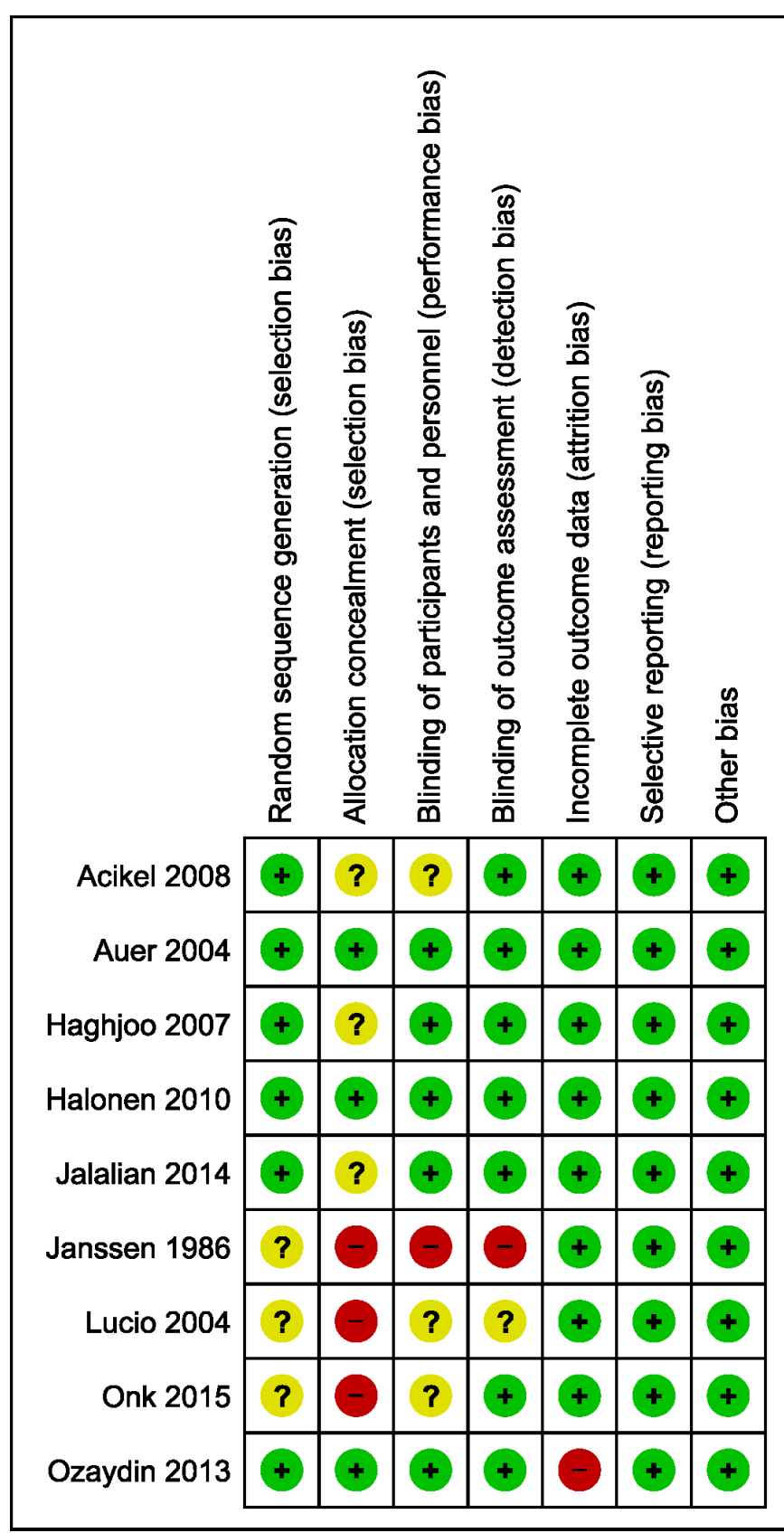

Figure 3 A summary of the risk of bias according to review authors' judgements about each risk of bias item for each included study.

indicating similarities among the trials with regards to population, intervention and comparator of the outcome tested. We did not perform subgroup analysis according to the dosage of drugs due to the limited number of trials, and its indication in the presence of high heterogeneity. The GRADE quality assessment was high (table 3). In the metoprolol versus sotalol comparison, two trials reported the occurrence of POAF $^{2024}$ (205 patients; RR 1.79, 95\% CI 0.24 to $13.52 ; \mathrm{p}=0.570 ; \mathrm{I}^{2}=73 \%$ ) (see online supplemental figure 1). The GRADE quality assessment was low (table 4). In the metoprolol versus amiodarone comparison, two trials reported the occurrence of $\mathrm{POAF}^{1819}(567$ patients; RR 0.99 , 95\% CI 0.71 to $1.39 ; \mathrm{p}=0.960 ; \mathrm{I}^{2}=0 \%$ ) (see online supplemental figure 2). The GRADE quality assessment was high (table 5).

\section{Stroke}

Stroke as a secondary outcome was reported for the metoprolol versus amiodarone comparison, and two trials reported the occurrence of stroke ${ }^{1819}$ (567 patients; RR $1.45,95 \%$ CI 0.50 to $4.16 ; \mathrm{p}=0.490 ; \mathrm{I}^{2}=0 \%$ ) (see online supplemental figure 3 ). The GRADE quality assessment was moderate (table 5).

\section{Hypotension}

Hypotension as a secondary outcome was reported for the metoprolol versus placebo comparison, and two trials reported the occurrence of hypotension after administration of drugs $^{2021}$ (327 patients; RR 1.40, 95\% CI 0.03 to $56.55 ; \mathrm{p}=0.180 ; \mathrm{I}^{2}=68 \%$ ) (see online supplemental figure 4). The GRADE quality assessment was moderate (table 2).

\section{Bradycardia}

Bradycardia as a secondary outcome was reported for the metoprolol versus placebo comparison, and two trials reported the occurrence of bradycardia after drug administration $^{2021}$ (327 patients; RR 2.28, 95\% CI 0.91 to 6.22; $\mathrm{p}=0.080 ; \mathrm{I}^{2}=0 \%$ ) (see online supplemental figure 5 ). The GRADE quality assessment was moderate (table 2 ).

\section{Death}

This secondary outcome was reported for the metoprolol versus amiodarone comparison, and two trials reported the occurrence of death ${ }^{18} 19$ (567 patients; RR=0.96, 95\% CI 0.20 to $4.70 ; \mathrm{p}=0.960 ; \mathrm{I}^{2}=0 \%$ ) (see online supplemental figure 6 ). The GRADE quality assessment was moderate (table 5).

\section{Subgroup and sensitivity analysis}

The intended subgroup analyses for outcomes with high heterogeneity was not performed due to the limited number of trials. For sensitivity analyses, there

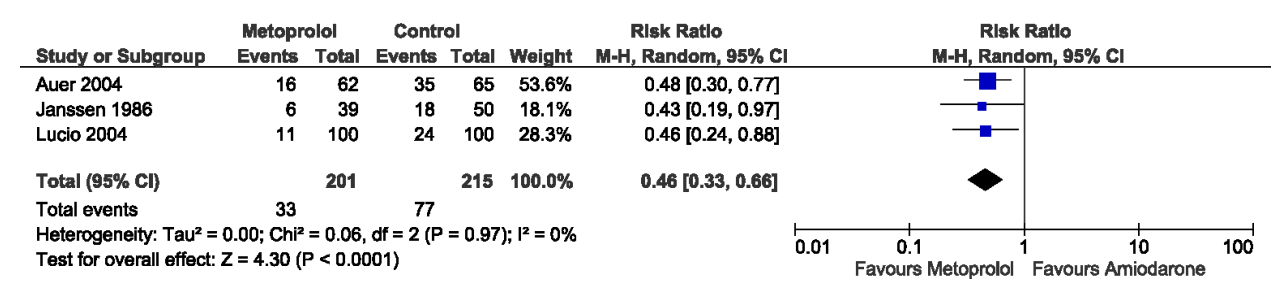

Figure 4 Individual and pooled effect size (risk ratio) of postoperative atrial fibrillation treated with metoprolol against placebo or no treatment. M-H, Mantel-Haenszel. 
Table 2 The grade quality assessment for metoprolol versus placebo or non-treatment group

Metoprolol compared with placebo or non-treatment for postoperative atrial fibrillation prophylaxis

Patient or population: cardiac surgery

Intervention: metoprolol

Comparison: placebo or non-treatment

\begin{tabular}{|c|c|c|c|c|c|c|}
\hline \multirow[b]{2}{*}{ Outcomes } & \multicolumn{2}{|c|}{$\begin{array}{l}\text { Anticipated absolute effects } \\
(95 \% \mathrm{Cl})^{\star}\end{array}$} & \multirow[b]{2}{*}{$\begin{array}{l}\text { Relative effect } \\
(95 \% \mathrm{Cl})\end{array}$} & \multirow{2}{*}{$\begin{array}{l}\text { No of } \\
\text { participants } \\
\text { (studies) }\end{array}$} & \multirow{2}{*}{$\begin{array}{l}\text { Certainty of } \\
\text { the evidence } \\
\text { (GRADE) }\end{array}$} & \multirow[b]{2}{*}{ Comments } \\
\hline & $\begin{array}{l}\text { Risk with } \\
\text { placebo }\end{array}$ & $\begin{array}{l}\text { Risk with } \\
\text { metoprolol }\end{array}$ & & & & \\
\hline \multirow{2}{*}{$\begin{array}{l}\text { Postoperative } \\
\text { atrial fibrillation }\end{array}$} & \multicolumn{2}{|c|}{ Study population } & \multirow{2}{*}{$\begin{array}{l}\text { RR } 0.46 \\
(0.32 \text { to } 0.66) \\
(p<0.001)\end{array}$} & \multirow{2}{*}{$\begin{array}{l}416 \\
\text { (3 RCTs) }\end{array}$} & \multirow{2}{*}{$\begin{array}{l}\bigoplus \bigoplus \bigoplus \bigoplus \\
\mathrm{HIGH}\end{array}$} & \multirow{2}{*}{$\begin{array}{l}\text { Assumed risk calculated } \\
\text { from the mean risk across } \\
\text { the control groups }\end{array}$} \\
\hline & 358 per 1000 & $\begin{array}{l}165 \text { per } 1000 \\
(115 \text { to } 236)\end{array}$ & & & & \\
\hline Hypotension & 12 per 1000 & $\begin{array}{l}21 \text { per } 1000 \\
(5 \text { to } 87)\end{array}$ & $\begin{array}{l}\text { RR } 1.70 \\
(0.41 \text { to } 7.16) \\
(p=0.860)\end{array}$ & $\begin{array}{l}327 \\
(2 \mathrm{RCTs})\end{array}$ & $\begin{array}{l}\bigoplus \bigoplus \bigoplus \bigoplus \\
\mathrm{HIGH}\end{array}$ & $\begin{array}{l}\text { Assumed risk calculated } \\
\text { from the mean risk across } \\
\text { the control groups }\end{array}$ \\
\hline \multirow[t]{2}{*}{ Bradycradia } & \multicolumn{2}{|c|}{ Study population } & RR 2.55 & 327 & $\oplus \oplus \oplus \oplus$ & Assumed risk calculated \\
\hline & 30 per 1000 & $\begin{array}{l}77 \text { per } 1000 \\
(30 \text { to } 200)\end{array}$ & $\begin{array}{l}(0.99 \text { to } 6.60) \\
(p=0.080)\end{array}$ & (2 RCTs) & $\mathrm{HIGH}$ & $\begin{array}{l}\text { from the mean risk across } \\
\text { the control groups }\end{array}$ \\
\hline
\end{tabular}

GRADE Working Group grades of evidence.

High certainty: We are very confident that the true effect lies close to that of the estimate of the effect.

Moderate certainty: We are moderately confident in the effect estimate: The true effect is likely to be close to the estimate of the effect, but there is a possibility that it is substantially different.

Low certainty: Our confidence in the effect estimate is limited: The true effect may be substantially different from the estimate of the effect. Very low certainty: We have very little confidence in the effect estimate: The true effect is likely to be substantially different from the estimate of effect.

${ }^{*}$ The risk in the intervention group (and its $95 \% \mathrm{Cl}$ ) is based on the assumed risk in the comparison group and the relative effect of the intervention (and its $95 \% \mathrm{Cl}$ ).

GRADE, grading of recommendations assessment, development and evaluation; RCTs, randomised controlled trials; RR, risk ratio.

was no substantial change in the effect sizes or CI of all the outcomes with an unclear risk of bias for allocation concealment and random sequence generation.

\section{DISCUSSION}

This review was designed to include all RCTs that focused on the effectiveness of metoprolol on the occurrence of POAF in heart surgery patients. The nine identified trials addressed several comparisons of drugs and outcomes with specified objectives. Metoprolol significantly reduced POAF compared with placebo, and there were no differences in the occurrence of side effects, which were hypotension and bradycardia in the two groups. In the metoprolol versus carvedilol comparison, metoprolol increased the risk of POAF compared with carvedilol. There was no difference compared with sotalol or amiodarone in the occurrence of POAF. For the metoprolol versus amiodarone group, there was no difference in the occurrence of stroke and death.

We performed a comprehensive and extensive literature review for assessing the effectiveness of metoprolol on the occurrence of POAF in heart surgery patients. We included nine trials that focused on patients undergoing revascularisation surgery and valvular heart surgery. The intervention group in each trial took metoprolol, and the control groups ranged from placebo to carvedilol, sotalol and amiodarone. The time of drug administration and doses given to the patients were different in each trial, thereby limiting the applicability of the findings in this review. We tried to use subgroup analysis to assess the dosage, routes of administration and the time at which the treatment was initiated, but there were limited number of

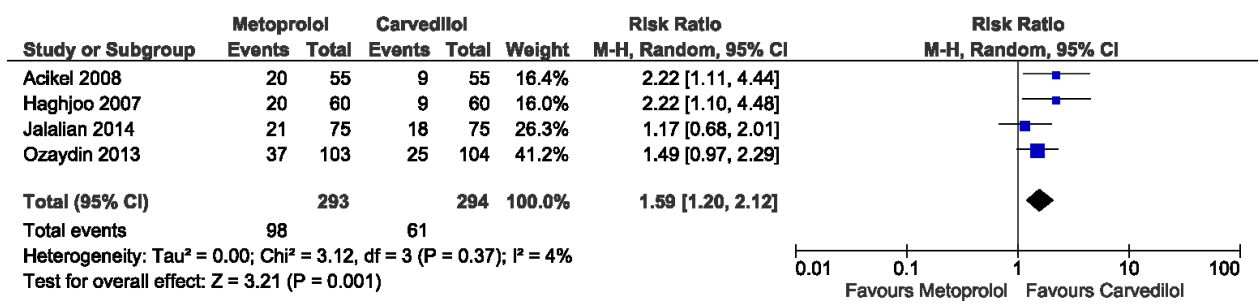

Figure 5 Individual and pooled effect size (risk ratio) of postoperative atrial fibrillation treated with metoprolol compared with carvedilol. M-H, Mantel-Haenszel. 
Table 3 The grade quality assessment for metoprolol versus carvedilol

\section{Metoprolol compared with carvedilol for postoperative atrial fibrillation prophylaxis}

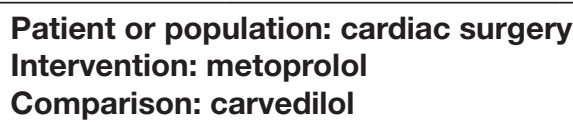

\begin{tabular}{|c|c|c|c|c|c|c|}
\hline \multirow[b]{2}{*}{ Outcomes } & \multicolumn{2}{|c|}{ Anticipated absolute effects $(95 \% \mathrm{Cl})^{*}$} & \multirow{2}{*}{$\begin{array}{l}\text { Relative effect } \\
(95 \% \mathrm{CI})\end{array}$} & \multirow{2}{*}{$\begin{array}{l}\text { No of } \\
\text { participants } \\
\text { (studies) }\end{array}$} & \multirow{2}{*}{$\begin{array}{l}\text { Certainty of } \\
\text { the evidence } \\
\text { (GRADE) }\end{array}$} & \multirow[b]{2}{*}{ Comments } \\
\hline & Risk with carvedilol & $\begin{array}{l}\text { Risk with } \\
\text { metoprolol }\end{array}$ & & & & \\
\hline $\begin{array}{l}\text { Occurrence of } \\
\text { postoperative } \\
\text { atrial fibrillation }\end{array}$ & $\begin{array}{l}\text { Study population } \\
207 \text { per } 1000\end{array}$ & $\begin{array}{l}334 \text { per } 1000 \\
\text { (253 to } 442)\end{array}$ & $\begin{array}{l}\text { RR } 1.61 \\
(1.22 \text { to } 2.13) \\
(p<0.001)\end{array}$ & $\begin{array}{l}587 \\
\text { (4 RCTs) }\end{array}$ & $\begin{array}{l}\bigoplus \bigoplus \bigoplus \bigoplus \\
\mathrm{HIGH}\end{array}$ & $\begin{array}{l}\text { Assumed risk } \\
\text { calculated from the } \\
\text { mean risk across } \\
\text { the control groups }\end{array}$ \\
\hline
\end{tabular}

GRADE Working Group grades of evidence.

High certainty: We are very confident that the true effect lies close to that of the estimate of the effect.

Moderate certainty: We are moderately confident in the effect estimate: The true effect is likely to be close to the estimate of the effect, but there is a possibility that it is substantially different.

Low certainty: Our confidence in the effect estimate is limited: The true effect may be substantially different from the estimate of the effect. Very low certainty: We have very little confidence in the effect estimate: The true effect is likely to be substantially different from the estimate of effect.

${ }^{*}$ The risk in the intervention group (and its $95 \% \mathrm{Cl}$ ) is based on the assumed risk in the comparison group and the relative effect of the intervention (and its $95 \% \mathrm{Cl}$ ).

GRADE, grading of recommendations assessment, development and evaluation; RCTs, randomised controlled trials; RR, risk ratio.

trials to enable to do so. We cannot determine whether earlier or prolonged administration of the drugs would affect the occurrence of POAF. Few trials included the adverse effects of surgeries, which limited the process of examining the efficacy and safety of the drugs used.

We found that the quality of evidence in the trials for the primary outcome was variable; mainly ranging from moderate to high. Although there were unclear and high risk of bias in some risk of bias assessments, we think that these risks are not significant for the review. All these trials had a short follow-up in the acute phase, with an objective assessment that was unlikely to affect the outcome. For most of our meta-analyses, we encountered little heterogeneity among the participants. We tried to reduce publication bias by checking the reference lists of all related studies for further references and searching multiple databases, but we restricted the search to English language publications due to the language barrier. Despite the vigorous search of journal databases, we cannot be sure that we have extracted all trials relevant to our review.

Table 4 The grade quality assessment for metoprolol versus sotalol

Metoprolol compared with sotalol for postoperative atrial fibrillation prophylaxis

\section{Patient or population: cardiac surgery \\ Intervention: metoprolol \\ Comparison: sotalol}

\begin{tabular}{|c|c|c|c|c|c|c|}
\hline \multirow[b]{2}{*}{ Outcomes } & \multicolumn{2}{|c|}{ Anticipated absolute effects $(95 \% \mathrm{Cl})^{*}$} & \multirow{2}{*}{$\begin{array}{l}\text { Relative effect } \\
(95 \% \mathrm{Cl})\end{array}$} & \multirow{2}{*}{$\begin{array}{l}\text { No of } \\
\text { participants } \\
\text { (studies) }\end{array}$} & \multirow{2}{*}{$\begin{array}{l}\text { Certainty of } \\
\text { the evidence } \\
\text { (GRADE) }\end{array}$} & \multirow{2}{*}{ Comments } \\
\hline & Risk with sotalol & $\begin{array}{l}\text { Risk with } \\
\text { metoprolol }\end{array}$ & & & & \\
\hline $\begin{array}{l}\text { Postoperative } \\
\text { atrial fibrillation }\end{array}$ & $\begin{array}{l}\text { Study population } \\
202 \text { per } 1000\end{array}$ & $\begin{array}{l}216 \text { per } 1000 \\
\text { (129 to } 363)\end{array}$ & $\begin{array}{l}\text { RR } 1.07 \\
(0.64 \text { to } 1.80) \\
(p=0.570)\end{array}$ & $\begin{array}{l}205 \\
\text { (2 RCTs) }\end{array}$ & $\begin{array}{l}\oplus \oplus \oplus \oplus \\
\mathrm{HIGH}\end{array}$ & $\begin{array}{l}\text { Assumed risk } \\
\text { calculated from the } \\
\text { mean risk across } \\
\text { the control groups }\end{array}$ \\
\hline
\end{tabular}

GRADE Working Group grades of evidence.

High certainty: We are very confident that the true effect lies close to that of the estimate of the effect.

Moderate certainty: We are moderately confident in the effect estimate: The true effect is likely to be close to the estimate of the effect, but there is a possibility that it is substantially different.

Low certainty: Our confidence in the effect estimate is limited: The true effect may be substantially different from the estimate of the effect. Very low certainty: We have very little confidence in the effect estimate: The true effect is likely to be substantially different from the estimate of effect.

${ }^{*}$ The risk in the intervention group (and its $95 \% \mathrm{Cl}$ ) is based on the assumed risk in the comparison group and the relative effect of the intervention (and its $95 \% \mathrm{Cl}$ ).

GRADE, grading of recommendations assessment, development and evaluation; RCTs, randomised controlled trials; RR, risk ratio. 
Table 5 The grade quality assessment for metoprolol versus amiodarone

\section{Metoprolol compared with amiodarone for postoperative atrial fibrillation prophylaxis}

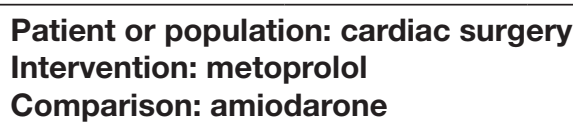

\begin{tabular}{|c|c|c|c|c|c|c|}
\hline \multirow[b]{2}{*}{ Outcomes } & \multicolumn{2}{|c|}{$\begin{array}{l}\text { Anticipated absolute effects } \\
(95 \% \mathrm{Cl})^{\star}\end{array}$} & \multirow[b]{2}{*}{$\begin{array}{l}\text { Relative effect } \\
(95 \% \mathrm{Cl})\end{array}$} & \multirow{2}{*}{$\begin{array}{l}\text { No of } \\
\text { participants } \\
\text { (studies) }\end{array}$} & \multirow{2}{*}{$\begin{array}{l}\text { Certainty of } \\
\text { the evidence } \\
\text { (GRADE) }\end{array}$} & \multirow{2}{*}{ Comments } \\
\hline & $\begin{array}{l}\text { Risk with } \\
\text { amiodarone }\end{array}$ & $\begin{array}{l}\text { Risk with } \\
\text { metoprolol }\end{array}$ & & & & \\
\hline \multirow{2}{*}{$\begin{array}{l}\text { Postoperative atrial } \\
\text { fibrillation }\end{array}$} & \multicolumn{2}{|l|}{ Study population } & \multirow{2}{*}{$\begin{array}{l}\text { RR } 0.99 \\
(0.71 \text { to } 1.39) \\
(p=0.960)\end{array}$} & \multirow{2}{*}{$\begin{array}{l}567 \\
\text { (2 RCTs) }\end{array}$} & \multirow{2}{*}{$\begin{array}{l}\bigoplus \bigoplus \bigoplus \bigoplus \\
\mathrm{HIGH}\end{array}$} & \multirow{2}{*}{$\begin{array}{l}\text { Assumed risk calculated } \\
\text { from the mean risk across } \\
\text { the control groups }\end{array}$} \\
\hline & 190 per 1000 & $\begin{array}{l}188 \text { per } 1000 \\
(135 \text { to } 264)\end{array}$ & & & & \\
\hline Stroke & 18 per 1000 & $\begin{array}{l}26 \text { per } 1000 \\
(9 \text { to } 75)\end{array}$ & $\begin{array}{l}\text { RR } 1.47 \\
(0.51 \text { to } 4.20) \\
(p=0.490)\end{array}$ & $\begin{array}{l}567 \\
(2 \mathrm{RCTs})\end{array}$ & $\begin{array}{l}\bigoplus \bigoplus \bigoplus \bigoplus \\
\mathrm{HIGH}\end{array}$ & $\begin{array}{l}\text { Assumed risk calculated } \\
\text { from the mean risk across } \\
\text { the control groups }\end{array}$ \\
\hline \multirow[t]{2}{*}{ Death } & \multicolumn{2}{|l|}{ Study population } & RR 0.96 & 567 & $\oplus \oplus \oplus \oplus$ & Assumed risk calculated \\
\hline & Eleven per 1000 & $\begin{array}{l}\text { Ten per } 1000 \\
(2 \text { to } 51)\end{array}$ & $\begin{array}{l}(0.20 \text { to } 4.70) \\
(p=0.960)\end{array}$ & (2 RCTs) & $\mathrm{HIGH}$ & $\begin{array}{l}\text { from the mean risk across } \\
\text { the control groups }\end{array}$ \\
\hline
\end{tabular}

GRADE Working Group grades of evidence.

High certainty: We are very confident that the true effect lies close to that of the estimate of the effect.

Moderate certainty: We are moderately confident in the effect estimate: The true effect is likely to be close to the estimate of the effect, but there is a possibility that it is substantially different.

Low certainty: Our confidence in the effect estimate is limited: The true effect may be substantially different from the estimate of the effect. Very low certainty: We have very little confidence in the effect estimate: The true effect is likely to be substantially different from the estimate of effect.

${ }^{*}$ The risk in the intervention group (and its $95 \% \mathrm{Cl}$ ) is based on the assumed risk in the comparison group and the relative effect of the intervention (and its $95 \% \mathrm{Cl}$ ).

GRADE, grading of recommendations assessment, development and evaluation; RCTs, randomised controlled trials; RR, risk ratio.

The use of beta-blockers significantly reduces the POAF rate in cardiac surgery patients. ${ }^{1}$ From the results of our review, we found that metoprolol significantly reduced POAF after cardiac surgery compared with the placebo, but it was not superior to carvedilol, sotalol or amiodarone. However, the comparison with sotalol has low quality of evidence and was limited by the small number of samples. One meta-analysis found that carvedilol is better than metoprolol in reducing POAF after cardiac surgery, ${ }^{7}$ and one review agreed that carvedilol is superior to metoprolol in this regard. ${ }^{8} \mathrm{~A}$ meta-analysis reported a greater than $30 \%$ risk reduction with sotalol compared with other beta-blockers, including metoprolol. ${ }^{26} \mathrm{~A}$ physician or cardiothoracic surgeon should be aware of the various beta-blockers available in their clinical practice. The selection should be based on the evidence available; for example, studies showed that carvedilol is still superior but in cases when it is not available, then other beta-blockers would be of choice.

\section{CONCLUSIONS}

In this study, metoprolol was found to be effective compared with placebo and showed no difference with class III antiarrhythmic drugs. Side effects, such as hypotension and bradycardia, was not found to be significant in this study; thus, we can say that metoprolol is relatively safe for POAF prophylaxis.

Correction notice The article has been corrected since it is published. The university name in affiliations 1 and 2 has been corrected.

Acknowledgements The authors would like to thank Amran Mamat and Nurul Azurah Mohd Roni, librarians from Hamdan Tahir Library, for their assistance with database searches.

Contributors MNN conceived the idea for the protocol and made the main contribution to planning and preparation of timelines for its completion. MNN and ZMA planned the data extraction and statistical analysis, as well as of risk of bias, quality of evidence and completeness of reporting assessments. ZMA and MI designed the tables and wrote the first draft of the manuscript, which was then reviewed and amended by ISB, SZ, NHNH, ZMA and MI. All authors then approved the final written manuscript. MNN is the guarantor for the work.

Funding The authors have not declared a specific grant for this research from any funding agency in the public, commercial or not-for-profit sectors.

Competing interests None declared.

Patient consent for publication Not required.

Provenance and peer review Not commissioned; externally peer reviewed.

Data availability statement All data relevant to the study are included in the article or uploaded as online supplemental information. No unpublished data are available.

Supplemental material This content has been supplied by the author(s). It has not been vetted by BMJ Publishing Group Limited (BMJ) and may not have been peer-reviewed. Any opinions or recommendations discussed are solely those of the author(s) and are not endorsed by BMJ. BMJ disclaims all liability and responsibility arising from any reliance placed on the content. Where the content includes any translated material, BMJ does not warrant the accuracy and reliability 
of the translations (including but not limited to local regulations, clinical guidelines, terminology, drug names and drug dosages), and is not responsible for any error and/or omissions arising from translation and adaptation or otherwise.

Open access This is an open access article distributed in accordance with the Creative Commons Attribution Non Commercial (CC BY-NC 4.0) license, which permits others to distribute, remix, adapt, build upon this work non-commercially, and license their derivative works on different terms, provided the original work is properly cited, appropriate credit is given, any changes made indicated, and the use is non-commercial. See: http://creativecommons.org/licenses/by-nc/4.0/.

\section{ORCID iDs}

Mohd Noor Norhayati http://orcid.org/0000-0002-6372-1476

Muhammad Irfan http://orcid.org/0000-0002-5308-2359

\section{REFERENCES}

1 Dobrev D, Aguilar M, Heijman J, et al. Postoperative atrial fibrillation: mechanisms, manifestations and management. Nat Rev Cardiol 2019;16:417-36.

2 Rho RW. The management of atrial fibrillation after cardiac surgery. Heart 2009;95:422-9.

3 Maisel WH, Rawn JD, Stevenson WG. Atrial fibrillation after cardiac surgery. Ann Intern Med 2001;135:1061-73.

4 Echahidi N, Pibarot P, O'Hara G, et al. Mechanisms, prevention, and treatment of atrial fibrillation after cardiac surgery. J Am Coll Cardiol 2008;51:793-801.

5 Greenberg JW, Lancaster TS, Schuessler RB, et al. Postoperative atrial fibrillation following cardiac surgery: a persistent complication. Eur J Cardiothorac Surg 2017;52:665-72.

6 Jalalian R, Ghafari R, Ghazanfari P. Comparing the therapeutic effects of carvedilol and metoprolol on prevention of atrial fibrillation after coronary artery bypass surgery, a double-blind study. Int Cardiovasc Res J 2014;8:111-5.

7 DiNicolantonio JJ, Beavers CJ, Menezes AR, et al. Meta-analysis comparing carvedilol versus metoprolol for the prevention of postoperative atrial fibrillation following coronary artery bypass grafting. Am J Cardiol 2014;113:565-9.

8 Zeinah M, Elghanam M, Benedetto U. Which beta-blocker should be used for the prevention of postoperative atrial fibrillation in cardiac surgery? A multi-treatment benefit-risk meta-analysis. The Egyptian Heart Journal 2016;68:89-96.

9 Higgins JPT, Thomas J, Chandler J, et al. Cochrane Handbook for shystematic heviews of interventions version 6.0: the Cochrane collaboration, 2019. Available: www.training.cochrane.org/handbook

10 Liberati A, Altman DG, Tetzlaff J, et al. The PRISMA statement for reporting systematic reviews and meta-analyses of studies that evaluate healthcare interventions: explanation and elaboration. BMJ 2009;339:b2700.

11 Guyatt GH, Oxman AD, Kunz R, et al. What is "quality of evidence" and why is it important to clinicians? BMJ 2008;336:995-8.
12 Cardinale D, Sandri MT, Colombo A, et al. Prevention of atrial fibrillation in high-risk patients undergoing lung cancer surgery: the presage trial. Ann Surg 2016;264:244-51.

13 Jakobsen CJ, Bille S, Ahlburg P, et al. Perioperative metoprolol reduces the frequency of atrial fibrillation after thoracotomy for lung resection. J Cardiothorac Vasc Anesth 1997;11:746-51.

14 Cagli K, Ozeke O, Ergun K, et al. Effect of low-dose amiodarone and magnesium combination on atrial fibrillation after coronary artery surgery. J Card Surg 2006;21:458-64.

15 Giri S, White CM, Dunn AB, et al. Oral amiodarone for prevention of atrial fibrillation after open heart surgery, the atrial fibrillation suppression trial (AFIST): a randomised placebo-controlled trial. Lancet 2001;357:830-6.

16 Cardona $\mathrm{F}$, Seide $\mathrm{H}$, Cox RA, et al. Effect of right atrial pacing, intravenous amiodarone and beta blockers for suppression of atrial fibrillation after coronary artery bypass surgery: a pilot study. $P R$ Health Sci J 2003;22:119-23.

17 Cheng N, Gao C. Prophylactic effects of metoprolol on the prevention of atrial fibrillation after cardiac surgery are dose dependent. Heart Surg Forum 2014;17:54-60.

18 Halonen J, Loponen $\mathrm{P}$, Järvinen $\mathrm{O}$, et al. Metoprolol versus amiodarone in the prevention of atrial fibrillation after cardiac surgery: a randomized trial. Ann Intern Med 2010;153:703-9.

19 Onk OA, Erkut B. Is the preoperative administration of amiodarone or metoprolol more effective in reducing atrial fibrillation: after coronary bypass surgery? Medicine 2015;94:e1576.

20 Auer J, Weber T, Berent R, et al. A comparison between oral antiarrhythmic drugs in the prevention of atrial fibrillation after cardiac surgery: the pilot study of prevention of postoperative atrial fibrillation (SPPAF), a randomized, placebo-controlled trial. Am Heart J 2004:147:636-43.

21 Lúcio EdeA, Flores A, Blacher C, et al. Effectiveness of metoprolol in preventing atrial fibrillation and flutter in the postoperative period of coronary artery bypass graft surgery. Arq Bras Cardiol 2004;82:4246-37-41.

22 Acikel S, Bozbas H, Gultekin B, et al. Comparison of the efficacy of metoprolol and carvedilol for preventing atrial fibrillation after coronary bypass surgery. Int J Cardiol 2008;126:108-13.

23 Haghjoo M, Saravi M, Hashemi MJ, et al. Optimal beta-blocker for prevention of atrial fibrillation after on-pump coronary artery bypass graft surgery: carvedilol versus metoprolol. Heart Rhythm 2007;4:1170-4

24 Janssen J, Loomans L, Harink J, et al. Prevention and treatment of supraventricular tachycardia shortly after coronary artery bypass grafting: a randomized open trial. Angiology 1986;37:601-9.

25 Ozaydin M, Icli A, Yucel H, et al. Metoprolol vs. carvedilol or carvedilol plus $\mathrm{N}$-acetyl cysteine on post-operative atrial fibrillation: a randomized, double-blind, placebo-controlled study. Eur Heart J 2013;34:597-604.

26 Wang H-S, Wang Z-W, Yin Z-T. Carvedilol for prevention of atrial fibrillation after cardiac surgery: a meta-analysis. PLoS One 2014;9:e94005. 